\title{
2'-O-methylation stabilizes Piwi-associated small RNAs and ensures DNA elimination in Tetrahymena
}

\author{
HENRIETTE M. KURTH and KAZUFUMI MOCHIZUKI \\ Institute of Molecular Biotechnology of the Austrian Academy of Sciences (IMBA), A-1030 Vienna, Austria
}

\begin{abstract}
Small RNAs $\sim 20-30$ nucleotides $(\mathrm{nt})$ in length regulate gene expression at the transcriptional and post-transcriptional levels. In the plant Arabidopsis, all small RNAs are $3^{\prime}$-terminal 2' -O-methylated by HEN1, whereas only a subset of small RNAs carry this modification in metazoans. This methylation is known to stabilize small RNAs, but its biological significance remains unclear. In the ciliated protozoan Tetrahymena thermophila, two classes of small RNAs have been identified: RNAs $\sim 28-29$ nt long (scnRNAs) that are expressed only during sexual reproduction, and constitutively expressed $\sim 23-24$ nt siRNAs. In this study, we demonstrate that scnRNAs, but not siRNAs, are $2^{\prime}-O$-methylated at their $3^{\prime}$ ends. The Tetrahymena HEN1 homolog Hen1p is responsible for scnRNA $2^{\prime}$ - $O$-methylation. Loss of Hen1p causes a gradual reduction in the level and length of scnRNAs, defects in programmed DNA elimination, and inefficient production of sexual progeny. Therefore, Hen1p-mediated 2'-O-methylation stabilizes scnRNA and ensures DNA elimination in Tetrahymena. This study clearly shows that $3^{\prime}$-terminal $2^{\prime}$-O-methylation on a selected class of small RNAs regulates the function of a specific RNAi pathway.
\end{abstract}

Keywords: HEN1; 2'-O-methylation; Piwi; DNA elimination; Tetrahymena

\section{INTRODUCTION}

Small noncoding RNAs produced by RNAi-related mechanisms regulate gene expression. They form functional effecter complexes with conserved Argonaute proteins, which can be divided into the Ago and Piwi subfamilies. Most eukaryotes possess a number of different ArgonauteRNA complexes, which are engaged in a wide variety of functions, including mRNA degradation, translational repression, and chromatin remodeling (for review, see Chu and Rana 2007).

Expression of small RNA is tightly regulated, mostly at the level of precursor RNA transcription (for example, see Johnson et al. 2003). In some cases, however, small RNA expression is post-transcriptionally regulated through control of precursor RNA processing (Obernosterer et a. 2006; Thomson et al. 2006; Yang et al. 2006a; Viswanathan et al. 2008). In addition, RNA degradation is likely to regulate the accumulation of small RNAs. One potential mechanism

Reprint requests to: Kazufumi Mochizuki, Institute of Molecular Biotechnology of the Austrian Academy of Sciences (IMBA), Dr. BohrGasse 3, A-1030 Vienna, Austria; e-mail: kazufumi.mochizuki@imba.oeaw. ac.at; fax: 43-1-79044-110.

Article published online ahead of print. Article and publication date are at http://www.rnajournal.org/cgi/doi/10.1261/rna.1455509. is the protection of small RNAs from degradation by $2^{\prime}-O-$ methylation at their $3^{\prime}$ terminus ( $\mathrm{Li}$ et al. 2005; Horwich et al. 2007).

In the plant Arabidopsis, all small RNAs (both si- and miRNAs) that have been studied are 2'-O-methylated at their $3^{\prime}$ ends. In contrast, in metazoans, only a subset of small RNAs carries $2^{\prime}$-O-methylation at their $3^{\prime}$ ends. In vertebrates, this modification has yet to be found on any miRNAs associated with Ago proteins that have been studied to date (Houwing et al. 2007; Kirino and Mourelatos 2007a; Ohara et al. 2007). In Drosophila, Ago2associated small RNAs (mainly siRNAs) are modified at their $3^{\prime}$ ends, most likely by $2^{\prime}$-O-methylation, whereas Agol-associated small RNAs (mainly miRNAs) are largely unmodified (Horwich et al. 2007; Kawamura et al. 2008). Interestingly, most if not all Piwi-associated small RNAs (piRNAs) are $2^{\prime}$-O-methylated at their $3^{\prime}$ ends in all metazoans that have been studied so far (Vagin et al. 2006; Horwich et al. 2007; Houwing et al. 2007; Kirino and Mourelatos 2007a; Ohara et al. 2007; Saito et al. 2007). Therefore, 3'-terminal 2'-O-methylation occurs on selected small RNAs, and it may regulate specific RNAi pathways in metazoans.

The RNA methyltransferase HEN1 is responsible for 3'-terminal 2'-O-methylation of small RNAs in Arabidopsis 
(Yu et al. 2005) and Drosophila (Horwich et al. 2007; Saito et al. 2007). Mouse HEN1 is also able to add 2'-O-methyl groups to small RNAs in vitro (Kirino and Mourelatos 2007b), but its role in vivo has yet to be studied. Arabidopsis HEN1 methylates double-stranded small RNAs (Yu et al. 2005; Yang et al. 2006b), probably before they are loaded into Argonaute proteins. This is consistent with the fact that all small RNAs are 2'-O-methylated, regardless of the Argonaute proteins to which they bind. In contrast, the HEN1 enzymes from Drosophila and mouse add 2'-O-methyl groups only to single-stranded small RNAs (Horwich et al. 2007; Saito et al. 2007). Thus, in these animals, 2'-O-methylation most likely occurs on small RNAs that have already complexed with Argonaute proteins. Drosophila HEN1 interacts with Piwi proteins (Piwi, Aubergine, and Ago3), whose binding partners (piRNAs) are 2'-O-methylated, but not with the Ago protein Ago1, whose small RNA partners are not modified (Saito et al. 2007). Therefore, the substrate specificity of HEN1 homologs in metazoans probably reflects the fact that HEN1 proteins interact with a specific class of Argonaute proteins.

The role of 3'-terminal 2'-O-methylation of small RNAs is well studied in Arabidopsis. Arabidopsis HEN1 mutants phenocopy the loss of activity of the general RNAi machinery, including Dicers and Argonautes (Chen et al. 2002; Boutet et al. 2003). This is because 2'-O-methylation protects small RNAs from degradation by exonucleases (Ramachandran and Chen 2008). The loss of this modification causes a general reduction in the levels of small RNAs in plants (Boutet et al. 2003; Li et al. 2005). Therefore, generally all small RNAs in Arabidopsis depend on $2^{\prime}$-O-methylation for their stability. Thus, this modification does not seem to control a specific RNAi pathway in plants.

In Drosophila mutant strains that lack the activity of the HEN1 homolog DmHEN1 (Pimet), the length and abundance of piRNAs, which are normally $2^{\prime}-O$-methylated at the $3^{\prime}$ end, are lower than in wild-type flies. In contrast, the levels of miRNAs, which are unmodified also in wild-type flies, are the same in both mutant and wild-type Drosophila (Horwich et al. 2007). Therefore, selective 2'-O-methylation of small RNAs regulates the turnover of a specific class of small RNAs, at least in flies. Horwich et al. (2007) reported that the HeT-A transposon mRNA was increased in the absence of DmHEN1. Nevertheless, because the Drosophila mutant strain lacking DmHEN1 is viable and fertile (Saito et al. 2007), the significance of this regulation remains unclear. Moreover, the functions of 2'-O-methylation of small RNAs in other eukaryotes have not been reported. Thus, despite the attractiveness of the idea that $3^{\prime}$-terminal $2^{\prime}$-O-methylation of a selected class of small RNAs regulates a specific RNAi pathway, this regulation has yet to be proven necessary for any biological process.

The ciliated protozoan Tetrahymena thermophila has 12 Piwi proteins, but no Ago proteins have been identified in the sequenced Tetrahymena genome. Tetrahymena expresses at least two classes of small RNAs generated by RNAi-related mechanisms. The first class comprises small RNAs of $\sim 28-29$ nucleotides (nt) (scnRNAs) that are expressed exclusively during sexual reproduction (conjugation) and are probably synthesized from many different genome loci (Chalker and Yao 2001; Mochizuki et al. 2002). scnRNAs bind specifically to the Piwi protein Twilp (Mochizuki and Gorovsky 2004), and the scnRNA-Twilp complex plays a pivotal role in developmentally programmed DNA elimination (Mochizuki et al. 2002). The other class of small RNAs consists of constitutively expressed siRNAs of $\sim 23-24 \mathrm{nt}$ that map to a small number of genomic loci (Lee and Collins 2006, 2007). The function of these siRNAs has not yet been identified.

In this study, we demonstrate that scnRNAs, but not siRNAs of $\sim 23-24 \mathrm{nt}$, are $2^{\prime}$-O-methylated by the Tetrahymena HEN1 homolog Hen1p. Hen1p-mediated 2'-Omethylation specifically stabilizes scnRNAs and ensures DNA elimination and the consequent survival of Tetrahymena progeny. Our findings lend support to the view that $3^{\prime}$-terminal 2'-O-methylation of a selected class of small RNAs regulates a specific RNAi pathway in eukaryotes.

\section{RESULTS}

\section{scnRNA, but not $\sim 23-24$ nt siRNA, is $2^{\prime}$-O-methylated}

T. thermophila expresses two classes of small RNAs made by RNAi-related mechanisms: RNAs of $\sim 28-29$ nt (scnRNAs) that are expressed only during sexual reproduction (Mochizuki et al. 2002) and constitutively expressed siRNAs of $\sim 23-$ 24 nt (Lee and Collins 2006).

In order to analyze whether scnRNAs are modified at their $3^{\prime}$ ends, total RNA from conjugating Tetrahymena cells enriched for scnRNAs was subjected to periodate oxidation/ $\beta$-elimination (Akbergenov et al. 2006). After these reactions, RNAs containing both $2^{\prime}$ - and $3^{\prime}$-hydroxyl groups at their $3^{\prime}$ ends are shorter by one nucleotide and they have an extra negative charge from the phosphate group left after the nucleotide removal. Modifications in $2^{\prime}$ - and/or $3^{\prime}$-hydroxyl groups prevent the periodate oxidation reaction and keep the RNA intact. As a result, unmodified RNA migrates as if it was $\sim 1.5 \mathrm{nt}$ shorter than the modified RNA in a denaturing polyacrylamide gel after the treatment. The mobility of the scnRNAs isolated at different stages of conjugation did not increase after periodate oxidation/ $\beta$-elimination, while unmodified control synthetic RNAs in the same reactions did (Fig. 1A). This result indicates that most, if not all, scnRNAs are modified at their $3^{\prime}$ ends throughout the process of conjugation.

To test whether the siRNAs of $\sim 23-24 \mathrm{nt}$ are modified at their $3^{\prime}$ ends, total RNA enriched for small RNAs was 


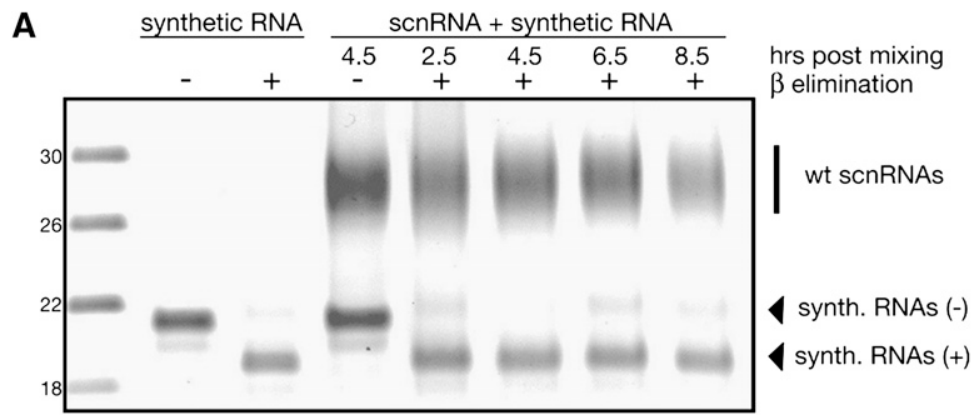

B
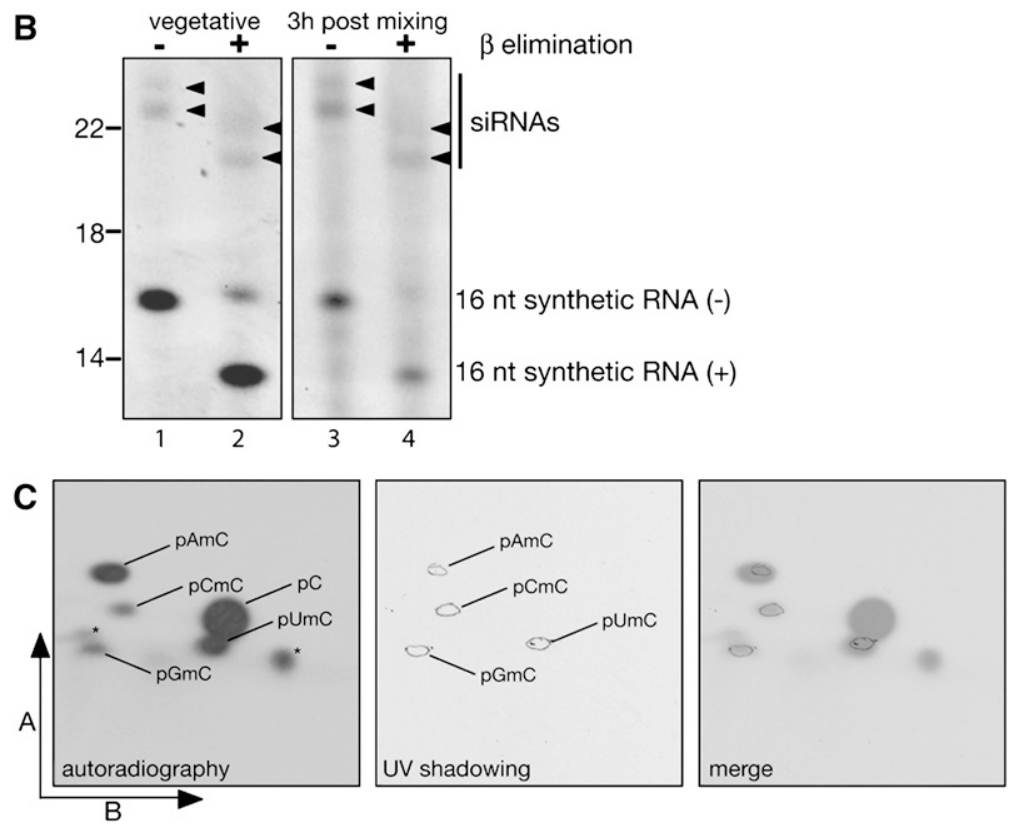

FIGURE 1. Tetrahymena scnRNAs are $2^{\prime}$-O-methylated at their $3^{\prime}$ ends. $(A)$ scnRNAs are modified at their $3^{\prime}$ ends throughout conjugation. Small RNAs isolated at different time points of conjugation $(2.5,4.5,6.5$, and $8.5 \mathrm{~h}$ post-mixing) were combined with a synthetic, $21-\mathrm{nt}$ RNA and subjected to periodate oxidation/ $\beta$-elimination. The reactions were subjected to denaturing gel electrophoresis and visualized using a nucleic acid-specific fluorescent dye. Untreated RNAs isolated from cells at $4.5 \mathrm{~h}$ post-mixing were analyzed in the same gel. The positions of the RNA markers are shown on the left. At all the stages tested, the mobility of the scnRNAs did not increase after the reaction, whereas that of the unmodified, synthetic 21-nt RNA did, indicating that scnRNAs were modified at their terminal nucleotides. $(B)$ The constitutively expressed small RNAs in Tetrahymena are not methylated. Small RNAs from vegetative (lane 2) and mating (lane 4) cells were subjected to periodate oxidation/ $\beta$ elimination. The reactions were separated in a denaturing gel, and the RNA was visualized using a nucleic acid staining dye. Untreated small RNAs (lane 1, vegetative cells; lane 3, mating cells) were analyzed on the same gel. The constitutively expressed siRNAs of $\sim 23-24 \mathrm{nt}$ (arrowheads) displayed a shift after the reaction. (C) scnRNAs are 2'-O-methylated. Gelpurified scnRNAs were radiolabeled by $\mathrm{pCp}$ ligation and treated with $\mathrm{P} 1$ nuclease. The reactants and the synthetic unlabeled dinucleotide standards (pCmpC, $\mathrm{pGmpC}, \mathrm{pAmpC}$, and pUmpC) were resolved by 2D-TLC on the same plate and visualized by autoradiography (left) and UV shadowing (middle). The four spots detected by UV shadowing are circled (middle), and their identities were determined by comparing the relative positions of these spots using a dinucleotide mobility map described previously (Keith 1995). Four radiolabeled spots comigrated with the dinucleotide standards (right), suggesting that scnRNAs were $2^{\prime}$ - $O$ methylated. Asterisks in the left panel indicate unidentified reaction products.

isolated from vegetatively growing and mating Tetrahymena and subjected to periodate oxidation $/ \beta$-elimination. As shown in Figure 1B, the mobility of endogenously expressed siRNAs of $\sim 23-24$ nt increased after this treatment, indicating that most, if not all, siRNAs of $\sim 23-24$ nt are not modified at their $3^{\prime}$ ends in vivo.

\section{scnRNA is $\mathbf{2}^{\prime}$-O-methylated}

Because the presence of a $3^{\prime}$-hydroxyl terminus on scnRNAs has been demonstrated previously (Mochizuki et al. 2002), the above result indicated a modification of the 2 '-hydroxyl termini of scnRNAs. We next tested whether this modification was 2'-O-methylation. PAGE-purified scnRNAs were ligated to $\left[5^{\prime}{ }^{32} \mathrm{P}\right]$ cytidine $5^{\prime}, 3^{\prime}$ bisphosphate (pCp) at the $3^{\prime}$-hydroxyl terminus, and the reaction products were digested with nuclease P1. Because the presence of a bulky modification at the 2 '-position reduces the rate at which nuclease P1 hydrolyzes the neighboring phosphodiester bond (Grosjean et al. 2007), RNA lacking such a modification produces cytidine 5 '-monophosphates $(\mathrm{pC})$ as a $\left[{ }^{32} \mathrm{P}\right]$-labeled product; in contrast, modified RNA produces labeled dinucleotides as well as pC. The digested scnRNA was resolved by two-dimensional thin-layer chromatography (2D-TLC) and analyzed by autoradiography (Fig. 1C, left). Synthetic 2'-O-methylated dinucleotides (pAmpC, $\mathrm{pCmpC}, \mathrm{pGmpC}$, and $\mathrm{pUmpC}$ ) were separated on the same plate and visualized by UV shadowing (Fig. 1C, middle). The migration distance of the four spots detected by autoradiography matched those of the synthetic 2'-Omethylated dinucleotide standards (Fig. $1 \mathrm{C}$, right), indicating that the $3^{\prime}$ termini of the scnRNAs were indeed modified by $2^{\prime}-O$-methylation.

\section{Hen1p has scnRNA methyltransferase activity in vitro}

In Arabidopsis, the RNA methyltransferase HEN1 modifies the terminal 2' hydroxyl group of siRNAs and miRNAs (Yu et al. 2005). In the fly and mouse, HEN1 homologs methylate terminal 2' hydroxyl groups of piRNAs (Horwich et al. 2007; Houwing et al. 2007; Kirino and Mourelatos 2007b; Ohara et al. 2007; Saito et al. 2007). The Tetrahymena genome possesses a single gene (TTHERM_00433810) that encodes a protein 
with strong similarity to these HEN1 homologs (Supplemental Fig. S1A,B). We named this gene HEN1. Hen 1p, the protein predicted from the HEN1 mRNA sequence (DDBJ/ EMBL/GenBank FM199973), has a conserved methyltransferase domain (Supplemental Fig. S1B). Although Arabidopsis HEN1 has a double-stranded RNA-binding domain, Tetrahymena Henlp lacks this domain, as do metazoan HEN1 proteins (Supplemental Fig. S1A).

To test whether Henlp has scnRNA methyltransferase activity, recombinant Henlp (rHenlp) was expressed in Escherichia coli. Purified rHen1p was incubated with synthetic RNAs of $29 \mathrm{nt}$ whose $3^{\prime}$ ends carried either a $2^{\prime}$ hydroxyl or a $2^{\prime}-O$-methyl and S-adenosyl-L[methyl- ${ }^{14} \mathrm{C}$ ] methionine, which served as a methyl group donor. rHen1p methylated the RNA with the $2^{\prime}$-hydroxyl terminus but did not methylate the RNA with a $2^{\prime}$-O-methyl terminus (Fig. 2A). These results indicate that Henlp can methylate the terminal 2'-hydroxyl group of scnRNAs.

rHen1p does not methylate double-stranded synthetic scnRNAs that possess blunt ends or $3^{\prime}$-overhangs of $2 \mathrm{nt}$, which mimic Dicer-processed RNA (Fig. 2A). This suggests that rHenlp methylates only single-stranded scnRNAs. Consistent with this, the gel mobility of scnRNAs in a TWI1 mutant strain, which is incapable of dissociating

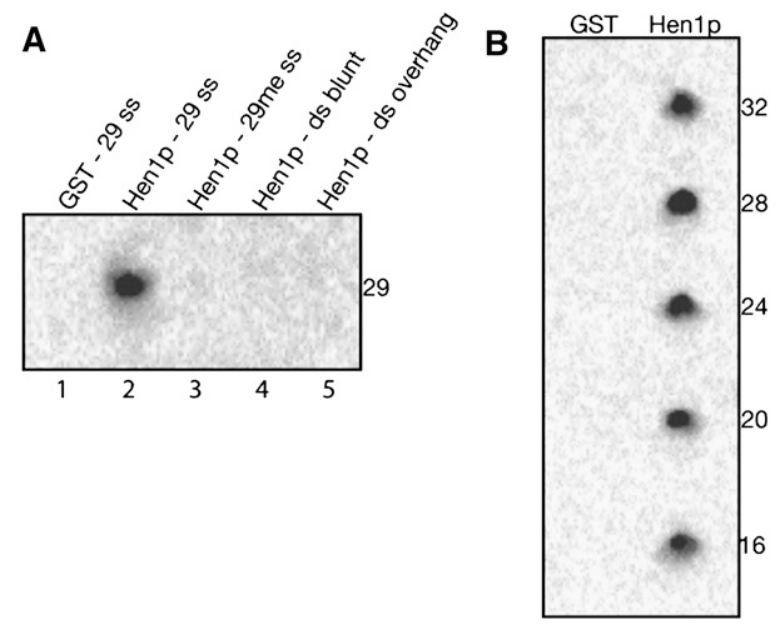

FIGURE 2. Tetrahymena Henlp methylates scnRNAs. (A) Recombinant Tetrahymena Henlp methylates single-stranded scnRNAs in vitro. Recombinant Tetrahymena Henlp (lanes 2-5) and control GST protein (lane 1) were incubated with S-adenosyl-L[methyl- ${ }^{14} \mathrm{C}$ ] methionine $\left(\left[{ }^{14} \mathrm{C}\right] \mathrm{SAM}\right)$ as a methyl donor and synthetic, singlestranded RNA of $29 \mathrm{nt}$ (lanes 1,2), single-stranded RNA of $29 \mathrm{nt}$ with a 2 '-O-methyl group at the terminal nucleotide (lane 3), and doublestranded RNAs of 29 bp with blunt ends (lane 4) or 3' 2-nt overhangs (lane 5). The reactions were analyzed by denaturing gel electrophoresis followed by autoradiography. Henlp transferred methyl groups only to single-stranded unmodified RNA (lane 2). (B) The activity of Henlp is not size-specific. Recombinant Tetrahymena Henlp was incubated with $\left[{ }^{14} \mathrm{C}\right] \mathrm{SAM}$ and synthetic RNAs of $16,20,24,28$, and $32 \mathrm{nt}$. The reaction was analyzed by denaturing gel electrophoresis followed by autoradiography. Henlp transferred methyl groups to RNA substrates of all sizes tested. double-stranded scnRNAs (T. Noto and K. Mochizuki, unpubl.), increased after periodate oxidation $/ \beta$-elimination treatment (Supplemental Fig. S3). We conclude that Hen $1 \mathrm{p}$ $2^{\prime}$-O-methylates only single-stranded scnRNAs both in vitro and in vivo. This also indicates that $2^{\prime}-O$-methylation of scnRNAs occurs after they are loaded into Twilp and the "passenger" strand of double-stranded scnRNA is removed.

rHen1p also transferred methyl groups to synthetic RNAs of 16, 20, 24, 28, and 32 nt (Fig. 2B). Therefore, at least in vitro, Hen1p can methylate not only scnRNAs of $\sim 28-29$ nt but also small RNAs that are the size of the siRNAs of $\sim 23-24$ nt constitutively expressed in Tetrahymena.

\section{Hen1p and Twi1p colocalize and interact}

An anti-Hen1p antibody was produced and used to study the expression and localization of Hen1p. Henlp was not detected by Western blotting in either vegetatively growing or starved cells (Fig. 3A), but HEN1 mRNA was detected in growing cells by RT-PCR (Supplemental Fig. S4). This suggests that vegetative cells may express a small amount of Henlp. Henlp was detected at a very early stage of conjugation at $2 \mathrm{~h}$ post-mixing, but the protein quickly disappeared thereafter (Fig. 3A). A similar result was obtained using immunofluorescent staining. Henlp was not detected in starved cells (Fig. 3B) but was first detected in the macronucleus when the micronucleus was in meiotic prophase at $\sim 2 \mathrm{~h}$ post-mixing (Fig. 3C,D). Henlp subsequently became undetectable in post-meiotic stages at $\sim 4$ h post-mixing (Fig. 3E). In conclusion, Hen $1 \mathrm{p}$ accumulation is developmentally regulated and specifically occurs in the macronucleus.

Both Henlp and the Piwi protein Twilp, which associates with scnRNA (Mochizuki and Gorovsky 2004), localize to the macronucleus during micronuclear meiotic prophase (Fig. 3C,F). We therefore examined whether Twilp and Henlp interact. Recombinant GST-Twilp was mixed with recombinant Henlp, and a pull-down assay was performed using glutathione beads. As a negative control, recombinant GST protein was used instead of GST-Twilp. Hen1p copurified with GST-Twilp, but not with GST (Fig. 3G), indicating that Henlp and Twilp directly interact.

\section{Hen1p is essential for scnRNA methylation in Tetrahymena}

To address whether Henlp is required for scnRNA methylation, HEN1 knockout (KO) Tetrahymena strains were constructed. The entire Henlp coding sequence of all polyploid macronuclear copies was replaced with a drug resistance marker in all HEN1 loci (Supplemental Fig. S5A,B). scnRNAs from HEN1 KO strains showed increased 
A
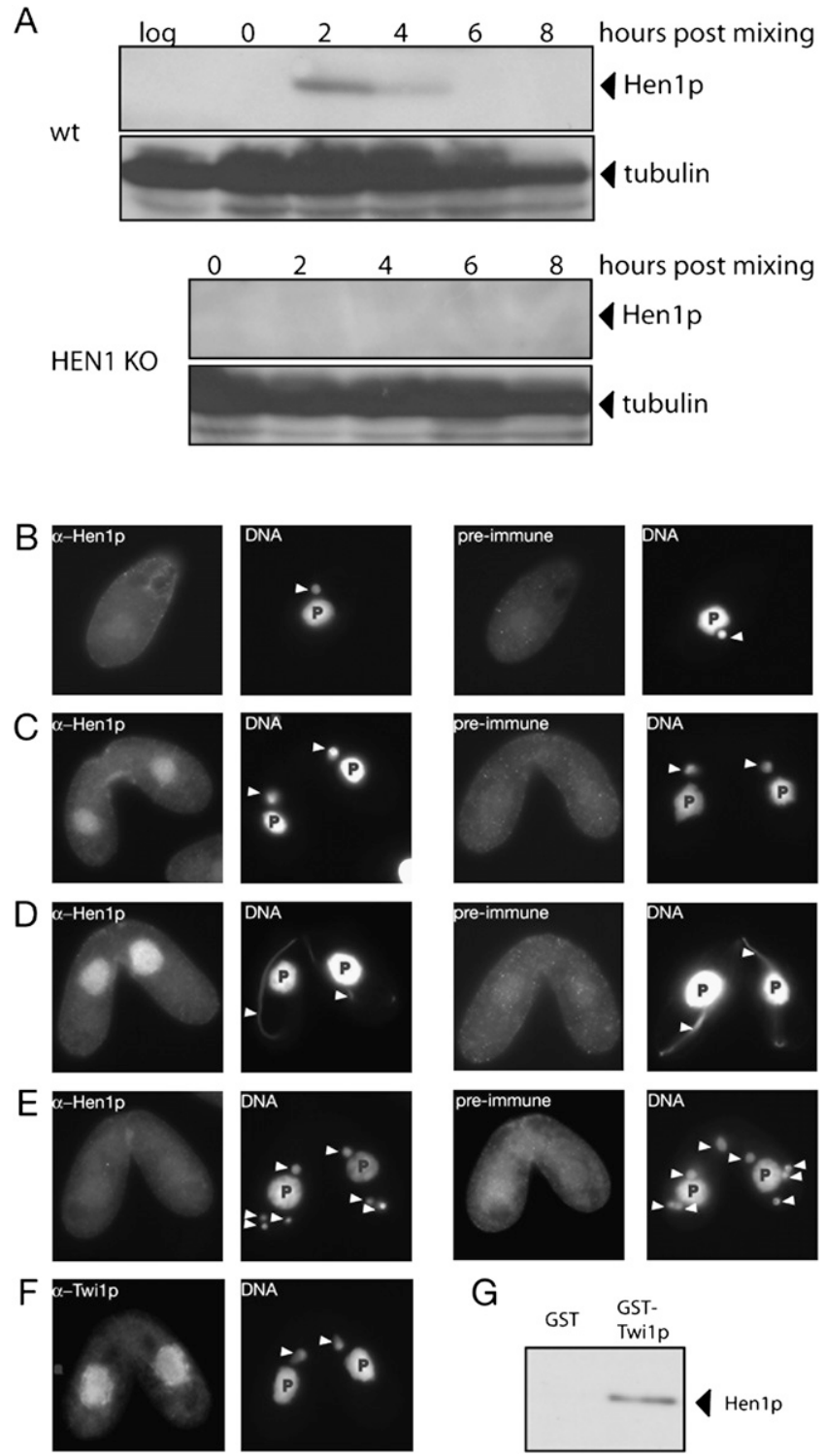

G

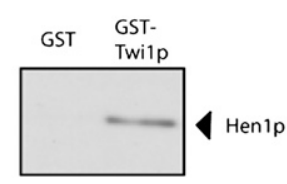

FIGURE 3. Henlp colocalizes and interacts with Twilp. (A) Henlp is expressed early in conjugation. Cell lysates were prepared at the vegetative growing stage $(\log )$ and at different developmental stages of sexual reproduction $(0 \mathrm{~h}$ post-mixing, before mating; $2 \mathrm{~h}$, Mic premeiosis; $4 \mathrm{~h}$, Mic meiosis; $6 \mathrm{~h}$, post-zygotic mitosis-Mac anlagen; $8 \mathrm{~h}$, new macronuclear development). For detailed developmental stages, see Cole et al. (1997). The lysate was analyzed by Western blotting using antibodies against Hen $1 \mathrm{p}($ top $)$ and $\alpha$-tubulin (bottom). Hen $1 \mathrm{p}$ was detected only during the early conjugation stage $(2-4 \mathrm{~h}$ postmixing). $(B-F)$ Henlp and Twilp localize in the parental macronucleus early in conjugation. Starved $(B)$ or mating (premeiosis, $C, D, F$; post-second meiosis, $E$ ) wild-type cells were processed for immunofluorescence using an anti-Henlp antibody (leftmost columns in $B-E$ ), preimmune serum (third column from the left of $B-E$ ), or an antiTwilp antibody $(F$, left). Cells were counterstained with DAPI (second and fourth columns from the left) to visualize the nuclei. Arrowheads indicate micronuclei; $\mathrm{P}$, parental macronuclei. $(G)$ Association between Henlp and Twilp. Recombinant GST (left) or GST-Twilp (right) was immobilized on glutathione beads and incubated with recombinant Hen 1p. After washing, proteins on the beads were eluted and analyzed by Western blotting using an anti-Henlp antibody. Henlp specifically bound to GST-Twilp but not to GST alone.

gel mobility after periodate oxidation $/ \beta$-elimination treatment (Fig. 4A), indicating that scnRNAs are not modified at their $3^{\prime}$ termini in the absence of HEN1. Therefore, HEN1 is essential for 2'-O-methylation of scnRNAs in Tetrahymena.

\section{Hen $1 p$ is essential for stable accumulation of scnRNAs}

Total RNA was extracted from wild-type and HEN1 KO cells, and scnRNA accumulation was analyzed at several different time points during conjugation. Although comparable levels of scnRNAs were detected in the early stages of conjugation ( $4 \mathrm{~h}$ post-mixing) in wild-type and HEN1 KO cells, the amount of scnRNAs from HEN1 KO cells in late stages of conjugation (6-10 $\mathrm{h}$ post-mixing) was substantially lower than in wild-type cells. In addition, the scnRNAs were gradually shortened by a few bases in the absence of HEN1 (Fig. 4B). In contrast, the accumulation of constitutively expressed siRNAs of $\sim 23-24$ nt was unaffected by the absence of HEN1 (Fig. 4B). Therefore, the turnover of scnRNAs and siRNAs of $\sim 23-24 \mathrm{nt}$ is independently regulated, and only scnRNAs are destabilized in the absence of Henlp. Since scnRNAs are synthesized only during the early stages of conjugation, these results suggest that Hen $1 \mathrm{p}$ protects scnRNA from degradation by $2^{\prime}$-O-methylating their $3^{\prime}$ ends.

\section{Viability of progeny is greatly reduced in HEN1 KO strains}

The HEN1 KO strains showed no obvious defects during vegetative growth (data not shown). They mated normally and produced exconjugants (progeny) containing new micro- and macronuclei (data not shown). Thus, at the cytological level, nuclear differentiation appeared to occur normally without HEN1.

To test the viability of progeny from the HEN1 KO strains, single mating pairs were placed into nutrient medium and their growth was analyzed. In wild-type cells, $\sim 40 \%$ of isolated pairs produced viable sexual progeny, whereas only $\sim 3 \%$ of HEN1 KO pairs gave rise to viable sexual progeny (Supplemental Fig. S5C). These data indicate that Henlp is not essential for the production of functional sexual progeny, but it does play an important role in the efficiency of this process.

\section{DNA elimination is inhibited in HEN1 KO strains}

In the sexual reproduction of Tetrahymena, the micronucleus produces both new micro- and macronuclei. During macronuclear development, $\sim 6000$ internal eliminated sequences (IESs) are removed, and the remaining macronucleardestined sequences are religated (for review, see Yao and Chao 2005). scnRNAs play essential roles in DNA elimination 


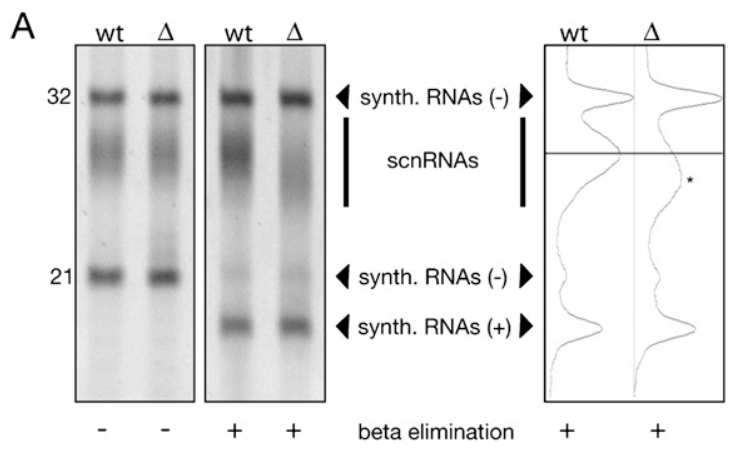

B

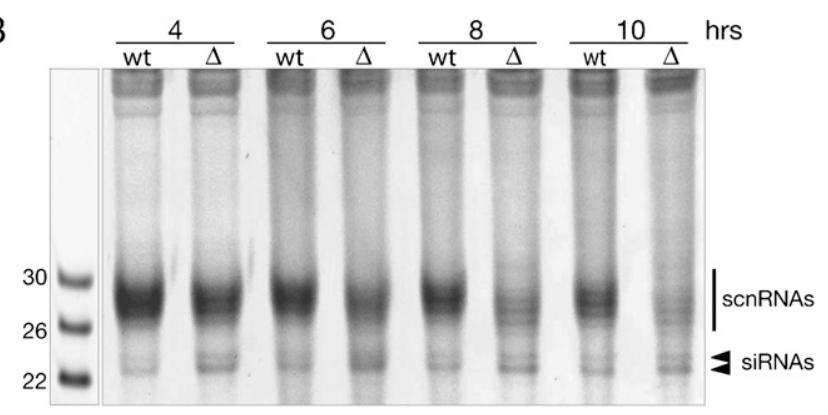

FIGURE 4. HEN1-mediated 2'-O-methylation stabilizes scnRNAs in Tetrahymena. (A) scnRNAs in HEN1 knockout $(\triangle H E N 1)$ cells are not modified. Small RNAs from wild-type (wt) and $\triangle H E N 1(\Delta)$ strains extracted at $4 \mathrm{~h}$ post-mixing were combined with synthetic, unmodified RNA of $21 \mathrm{nt}$ and were treated with $(+)$ or without $(-)$ periodate oxidation/ $\beta$-elimination. The reactions were then mixed with synthetic RNA of $32 \mathrm{nt}$ and analyzed by denaturing gel electrophoresis followed by staining with a nucleic acid-specific fluorescent dye (left). Densitometric analysis of the fluorescent signal is shown on the right. The gel mobility of scnRNAs from $\triangle H E N 1$ strains increased after the treatment, indicating that they have free $3^{\prime}$ hydroxyl groups. (B) scnRNAs are destabilized in $\triangle H E N 1$ strains. Total RNA from wildtype (wt) and $\triangle H E N 1(\Delta)$ strains was extracted at the indicated time points of conjugation, run on a sequencing gel, and stained with a nucleic acid-specific fluorescent dye. As conjugation proceeded, scnRNAs in $\triangle H E N 1$ cells became shorter and less abundant than wt scnRNAs at the same time points.

(for review, see Meyer and Chalker 2006). Therefore, we examined whether 2'-O-methylation of scnRNA plays a role in eliminating DNA in the new macronucleus.

We analyzed the elimination of four different IESs (M, R, Cal, and Tlr1 elements) (Austerberry et al. 1989; Katoh et al. 1993; Wells et al. 1994) in single sexual progeny (Fig. $5 \mathrm{~A}-\mathrm{C})$. In 18 of 56 progeny of the HEN1 KO strains, one or more of the four examined IES loci were not eliminated (Fig. 5C). In contrast, all of these loci were eliminated in the progeny of the control strain (Fig. 5C). Thus, we conclude that DNA elimination is affected in the absence of Hen1p. Although 38 of 56 progeny of the HEN1 KO strains showed complete or only reduced elimination of the four IESs, the removal of many of the other $\sim 6000$ IESs was likely to be affected in these progeny. Since DNA elimination is believed to be essential for producing viable sexual progeny (Coyne et al. 1999; Nikiforov et al. 1999;
Mochizuki et al. 2002; Liu et al. 2007; Aronica et al. 2008), the reduced production of viable offspring in the HEN1 KO strains (Supplemental Fig. S5C) is likely due to this partial DNA elimination defect.

\section{DISCUSSION}

\section{Function of 2'-O-methylation with respect to scnRNA}

In this study, we demonstrated that Tetrahymena scnRNAs are 2'-O-methylated by the RNA methyltransferase Hen1p.

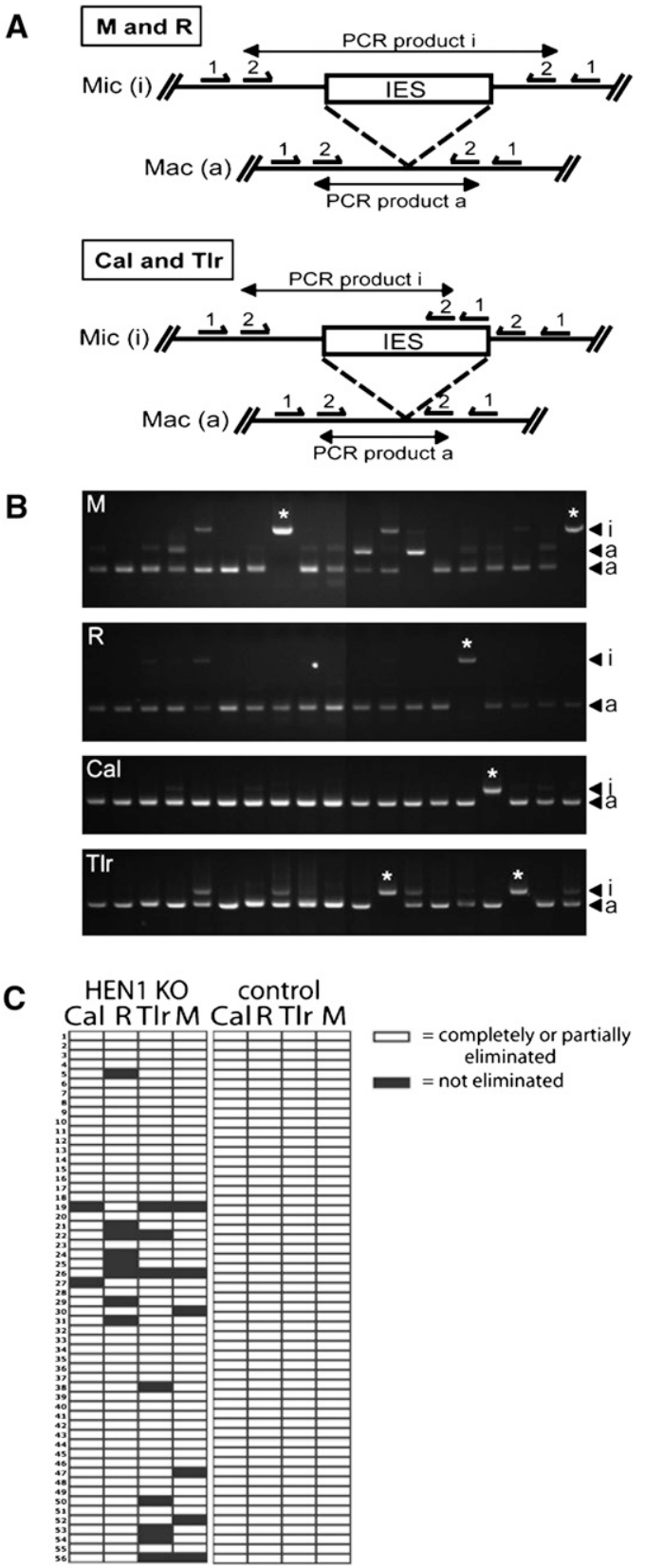

FIGURE 5. (Legend on next page) 
Loss of Hen $1 \mathrm{p}$ renders scnRNAs unstable, partially disables DNA elimination, and makes the production of sexual progeny inefficient. Since the defect in DNA elimination and production of sexual progeny can be explained by the instability of scnRNAs, we believe that the main function of $2^{\prime}$-O-methylation is scnRNA stabilization.

The manner by which $2^{\prime}$-O-methylation stabilizes scnRNAs remains unknown. It may directly protect scnRNA from exoribonuclease attack. Alternatively, scnRNAs lacking a $2^{\prime}$-O-methyl group may associate less tightly with Twilp, and dissociated scnRNAs may be more susceptible to ribonuclease degradation. In light of this suggestion, it is worth noting that the $3^{\prime}$ terminus of siRNA provides a binding site for the PAZ domains of human Agol and Ago2 (Ma et al. 2004; Lingel et al. 2004) and that scnRNAs are unstable in the absence of Twilp (Mochizuki and Gorovsky 2004).

Similar to the effects reported here for scnRNAs in Tetrahymena, HEN1-mediated 2'-O-methylation was reported to stabilize small RNAs in Arabidopsis and Drosophila (Chen et al. 2002; Li et al. 2005; Horwich et al. 2007). Plants can convey silencing information, which is probably mediated by siRNAs, over long distances (Hamilton et al. 2002; Klahre et al. 2002; Yoo et al. 2004). 2'-O-Methylation of siRNAs in plants may enable them to travel long distances, thus enhancing the defense against viruses (Boutet et al. 2003). In all metazoans studied to date, piRNAs are 2'-O-methylated (Vagin et al. 2006; Horwich et al. 2007; Houwing et al. 2007; Kirino and Mourelatos 2007a; Ohara et al. 2007; Saito et al. 2007) and Piwi proteins function primarily in germline cells (Cox et al. 1998; Deng and Lin 2002; Das et al. 2008). Since germline cells are transcriptionally inactive at certain developmental stages in many animals (Zalokar 1976; Newport and Kirschner 1982; Seydoux et al. 1996; Leatherman et al. 2002), piRNAs may

FIGURE 5. DNA elimination is affected in $\triangle H E N 1$ progeny. $(A)$ Schematic diagram of the IES elimination assay. Four primers per locus ( $\mathrm{M}$ and $\mathrm{R}$ loci, top) or six primers per locus (Cal and Tlr1 loci, bottom) were used for nested PCR. Primers marked 1 were used first, followed by those marked 2. Shorter Mac-form products (a) indicate that the locus was rearranged, whereas longer Mic-form products (i) indicate a defect in DNA elimination. (B) An example of the results of DNA elimination assays in $\triangle H E N 1$ progeny. Single cells were picked at $30 \mathrm{~h}$ post-mixing and used in nested PCR reactions as shown in $A$. $\mathrm{M}, \mathrm{R}, \mathrm{Cal}$, and Tlr1 loci were tested in each progeny cell for DNA elimination. Representative PCR results of 19 progenies of $\triangle H E N 1$ cells are shown. The positions of PCR products from unrearranged (i) and rearranged (a) loci are indicated. The progeny that showed only an unrearranged PCR product (highlighted with asterisks) in at least one of the four loci were counted as cells with defective DNA elimination. (C) Summary of the results obtained from 56 progeny cells of the $\triangle H E N 1$ and control cells. M, R, Cal, and Tlr1 loci were tested in each progeny cell (1-56) for DNA elimination. Open boxes indicate rearranged (a) DNA; filled boxes, unrearranged (i) DNA. Eighteen of 56 progeny cells from $\triangle H E N 1$ had DNA elimination defects in at least one of the four loci examined, whereas none of the progeny from control cells showed such defects. have to be $2^{\prime}$-O-methylated to increase their turnover time and ensure transposon silencing, even in the absence of their de novo production. Also, scnRNAs in Tetrahymena must be stable because they are produced at early stages of conjugation (Malone et al. 2005; Mochizuki and Gorovsky 2005) but they play a role in DNA elimination during late stages of conjugation. Thus, $2^{\prime}-O$-methylation appears to have evolved as a way to protect small RNAs from degradation in pathways that require their stable accumulation.

\section{A specific class of small RNAs is 2'-O-methylated in Tetrahymena}

We show in this study that scnRNAs, but not siRNAs of $\sim 23-24 \mathrm{nt}$, are 2'-O-methylated at their 3' ends. Therefore, only this specific class of small RNAs is $2^{\prime}-O$-methylated in the ciliate Tetrahymena. Since all 12 Argonaute proteins identified in Tetrahymena belong to the Piwi subfamily, the siRNAs of $\sim 23-24 \mathrm{nt}$ are most likely associated with some of those Piwi proteins. If this is the case, this is the first report describing Piwi-associated small RNAs that are not modified by $2^{\prime}-O$-methylation. This suggests that $2^{\prime}-O$-methylation is not a universal feature of Piwi-associated small RNAs.

Tetrahymena Hen $1 \mathrm{p}$ can methylate various sizes of small, single-stranded RNAs in vitro (Fig. 2B), whereas only scnRNAs seem to be methylated in vivo (Figs. 1A, 2C). This specific methylation of scnRNAs is likely ensured by (1) the restricted accumulation of Henlp early in conjugation (Fig. 3A), when scnRNAs begin to accumulate (Mochizuki et al. 2002); (2) the localization of Henlp to the parental macronucleus (Fig. 3B), where Twilp is also localized (see also Fig. 3F; Mochizuki et al. 2002); and (3) the interaction of Henlp with Twilp (Fig. 3G), which specifically binds to scnRNA (Mochizuki and Gorovsky 2004). The selective interaction between HEN1 protein and Piwi proteins has also been reported in Drosophila ovaries (Saito et al. 2007). In addition to this HEN1-Argonaute interaction, the specificity of small RNA 2'-O-methylation in metazoans may be controlled by the spatial and temporal regulation of HEN1 homolog expression, as in Tetrahymena.

\section{Evolution of piRNA biogenesis}

Although all detectable scnRNAs are methylated at their $3^{\prime}$ ends throughout conjugation (Fig. 1A), Henlp, which is responsible for methylating the $3^{\prime}$ end (Fig. 4A), only transiently appears during early conjugation (Fig. 3A-E). Therefore, scnRNAs that are present in the middle and later stages must have been methylated by Hen $1 p$ during the early stages of conjugation. This argues that most, if not all, scnRNAs are produced during the early stages of conjugation, when the Dicer homolog Dcllp processes micronuclear noncoding RNA to produce scnRNAs (Malone et al. 2005; Mochizuki and Gorovsky 2005). This also indicates that little or no secondary Dicer-independent scnRNA synthesis 
occurs during the later stages of conjugation. In addition, siRNAs of $\sim 23-24$ nt in Tetrahymena, which likely associate with Piwi proteins, are produced through a Dicer-dependent mechanism (Lee and Collins 2007). These processes differ markedly from the Dicer-independent production of piRNA in metazoans (Vagin et al. 2006; Houwing et al. 2007; Das et al. 2008; Wang and Reinke 2008). In Drosophila, it has been postulated that piRNAs are produced by sequential actions of the endoribonuclease (slicer) activities of Piwi proteins (Brennecke et al. 2007; Gunawardane et al. 2007). At this time, we cannot conclude whether the Dicer- or Piwi-dependent form of piRNA production is the ancestral form. It would be interesting to know how piRNAs are produced and whether all of these are 2'-O-methylated in Dictyostelium, which is an amoeba more closely related to metazoans than to ciliates.

\section{MATERIALS AND METHODS}

\section{Cell lines and culture conditions}

The wild-type CU428 and B2086 strains of T. thermophila were provided by Dr. P. J. Bruns (Cornell University). These strains are also available at the Tetrahymena Stock Center (Cornell University, http://tetrahymena.vet.cornell.edu). The cells were grown at $30^{\circ} \mathrm{C}$ in SPP medium (Gorovsky et al. 1975) containing $2 \%$ proteose peptone. Before mating, the cells were washed and resuspended $\left(5 \times 10^{5}\right.$ cells $\left./ \mathrm{mL}\right)$ in $10 \mathrm{mM}$ Tris buffer $(\mathrm{pH} 7.5)$. After $12-18 \mathrm{~h}$ of incubation at $30^{\circ} \mathrm{C}$, equal numbers of cells were mixed and mated. In the experiments shown in Figures 3A and $4 \mathrm{~B}$, the cultures were refed at 2 and $4 \mathrm{~h}$ post-mixing, respectively, by adding one-third volume of $4 \times$ SPP medium to limit the initiation of mating after that period.

\section{Analysis of small RNAs}

For the experiments shown in Figures $1 \mathrm{~A}$ and $4 \mathrm{~A}$ and Supplemental Figure S3, total RNA enriched in small RNAs was extracted using the mirVana Kit (Ambion). For the experiment shown in Figure 1B, total RNA was first extracted with Trizol (Invitrogen), and the small RNA fraction was enriched according to the method described by Lee and Collins (2006). For the experiment shown in Figure 4B, total RNA was extracted with Trizol. Oligo ribonucleotides were synthesized by Dharmacon. The periodate oxidation/ $\beta$-elimination reactions were performed as described (Akbergenov et al. 2006). RNA was separated in 12\%-20\% polyacrylamide-urea sequencing gels and was visualized using Gel Red (Biotium).

\section{Two-dimensional thin-layer chromatography}

Total RNA was isolated with Trizol (Invitrogen) at $4 \mathrm{~h}$ post-mixing and separated in a preparative sequencing gel; the scnRNAs $(\sim 26-$ $31 \mathrm{nt}$ ) were purified from the gel. The purified scnRNAs were ligated to $\left[5^{\prime}-{ }^{32} \mathrm{P}\right] \mathrm{pCp}$ using T4 RNA ligase (Amersham). The ligated scnRNAs-pCp were gel purified and digested for $20 \mathrm{~min}$ at $37^{\circ} \mathrm{C}$ using $\mathrm{P} 1$ nuclease ( $400 \mathrm{mU} / \mathrm{mL}$ final) (Sigma). The digest was mixed with synthetic 2'-O-methylated dinucleotide standards (pAmpC, pCmpC, pGmpC, and pUmpC), spotted onto HPTLC cellulose glass plates $(10 \times 10 \mathrm{~cm}$; Merck $)$, and resolved with isobutyric acid $/ 25 \%$ ammonium hydroxide/water (66:1:33 by volume) in the first dimension and then with isopropanol/ $\mathrm{HCl} /$ water (70:15:15 by volume) in the second dimension. The labeled dinucleotides were visualized by autoradiography, while the synthetic dinucleotide standards were visualized by UV shadowing.

\section{Expression and purification of Hen $1 p$ protein from $E$. coli}

Because of the differential codon usages in Tetrahymena, the entire Henlp coding sequence was synthesized (GenScript) for expression in E. coli. The sequence of the synthetic HEN1 gene is available upon request. The synthetic gene was subcloned into a modified pGEX-4T-1 vector (pGEX4T1-TEV), which has a TEV protease recognition sequence at the $\mathrm{C}$ terminus of the GST (gift from T. Clausen, IMP, Vienna) to allow production of a GSTTEV-Hen $1 p$ fusion protein. The construct was expressed in the E. coli BL21 (DE3) strain overnight at $25^{\circ} \mathrm{C}$ in the presence of $50 \mu \mathrm{M}$ IPTG. The proteins were purified using glutathione Sepharose 4B resin (GE Healthcare), and the recombinant Hen1p was eluted from the beads by cleaving the TEV sequence with AcTEV protease (Invitrogen).

\section{Methyltransferase assay}

In vitro methyltransferase assays were performed as described previously (Yu et al. 2005) with slight modifications. Hen $1 \mathrm{p}$ $(\sim 35 \mu \mathrm{g})$ was incubated for $5 \mathrm{~h}$ at $37^{\circ} \mathrm{C}$ with $0.6 \mathrm{nmol}$ of synthetic oligoribonucleotides (Dharmacon) (for sequences, see Supplemental Fig. S2) and $1.5 \mu \mathrm{Ci} \mathrm{S}$-adenosyl-L[methyl- $\left.{ }^{14} \mathrm{C}\right]$ methionine (Amersham). After proteinase $\mathrm{K}$ treatment, followed by phenol/ chloroform extraction and ethanol precipitation, half of the sample was separated in a thin $(0.5-\mathrm{mm}) 12 \%$ polyacrylamide-urea sequencing gel. The gel was dried, wrapped in Saran wrap, and exposed overnight to a storage phosphor screen (GE Healthcare). Images were captured using a Typhoon Imager (GE Healthcare) and analyzed using ImageQuant software (GE Healthcare).

\section{Indirect immunofluorescent staining}

Cells were fixed in 3.7\% formaldehyde and 0.5\% Triton-X 100 for $30 \mathrm{~min}$ at room temperature (RT), resuspended in $3.7 \%$ formaldehyde and $3.4 \%$ sucrose, and dried on poly-L-lysine (Sigma)coated cover slips. The samples were blocked for $1 \mathrm{~h}$ with $3 \%$ BSA (Sigma), 10\% normal goat serum (Invitrogen), and 0.1\% Tween 20 in PBS followed by overnight incubation at $4^{\circ} \mathrm{C}$ in blocking solution containing a 1:500 dilution of anti-Hen $1 \mathrm{p}$ or a 1:200 dilution of anti-Twilp (Aronica et al. 2008). The anti-Henlp antibody was obtained by immunizing a rabbit with recombinant Hen1p. After washes with PBT, samples were incubated with a 1:1000 dilution of anti-rabbit antibody conjugated with Alexa 488 (Invitrogen) for $1 \mathrm{~h}$ at RT. The samples were washed, incubated with $10 \mathrm{ng} / \mathrm{mL}$ DAPI (Sigma) in PBS, mounted with ProLong Gold (Invitrogen), and observed by fluorescent microscopy.

\section{RT-PCR}

Total RNA was extracted using TRIzol reagent (Invitrogen) from the wild-type strains B2086 and CU428, and residual genomic DNA was eliminated using the Turbo DNase Kit (Ambion). cDNA was 
synthesized from $5 \mu \mathrm{g}$ of total RNA using the RevertAid H Minus First Strand cDNA Synthesis Kit (Fermentas) and a random hexamer as a primer. cDNA from $12.5 \mathrm{ng}$ of total RNA was amplified by PCR (30 sec at $94^{\circ} \mathrm{C}, 30 \mathrm{sec}$ at $51^{\circ} \mathrm{C}, 40 \mathrm{sec}$ at $72^{\circ} \mathrm{C} ; 32 \mathrm{cycles}$ ) with primers $5^{\prime}$-AAAATTAATTCGAAGATGGTTCATAC- $3^{\prime}$ and 5'-TAGGAGAATAAGTTATCTGCAGTGG-3'.

\section{GST pull-down assay}

GST, GST-Twilp, and Henlp were expressed in E. coli and purified as described above. GST or GST-Twilp $(0.1 \mu \mathrm{g})$ were incubated for $30 \mathrm{~min}$ at $4^{\circ} \mathrm{C}$ with glutathione Sepharose $4 \mathrm{~B}$ resin (GE Healthcare) in GST pull-down buffer (GPB) (20 mM Tris at $\mathrm{pH}$ 7.5, $100 \mathrm{mM} \mathrm{NaCl}, 2 \mathrm{mM} \mathrm{MgCl}$, $2 \mathrm{mM} \mathrm{CaCl}_{2}, 10 \%$ glycerol, $0.1 \mathrm{mM}$ EDTA, $1 \mathrm{mM}$ DTT). The beads were washed once with $1 \%$ BSA in GPB and once with $0.1 \%$ BSA in GPB. Hen $1 \mathrm{p}(0.1 \mu \mathrm{g})$ was added, and the samples were incubated for $2 \mathrm{~h}$ at $4^{\circ} \mathrm{C}$. The beads were washed five times with $0.1 \%$ BSA in GPB and boiled in SDS loading buffer. The samples were loaded onto an SDS-PAGE gel, and the presence of Henlp was monitored by Western blotting using the anti-Henlp antibody.

\section{Construction of HEN1 KO strains}

The HEN1 KO construct (see Supplemental Fig. S5A) was generated by overlapping PCR. First, the $5^{\prime}$ UTR and $3^{\prime}$ UTR were amplified using the following primers (sequences overlapping with a neo4 cassette are underlined):

\section{5_UTR_fw, 5'-GGACTCGAGTGATAAAAATGAGTTGTTTGCT TATT-3'; \\ 5_UTR_rv, 5'-GTCTATCGAATTCCTGCAGCCCAAACCGGCT AGTTTTTACTTAG-3'; \\ 3_UTR_fw, 5' -CTGGAAAAATGCAGCCCTTGAAGCATTACAA AATAAATGG-3'; and \\ 3_UTR_rv, 5'-GGAATTCTCAACAACTAAATTCAAAC-3'.}

The products were combined with the neo 4 cassette (Mochizuki 2008) using 5_UTR_fw and 3_UTR_rv and the PCR extender system (5PRIME). The B2086 and CU428 wild-type strains were transformed with the PCR product as described (Cassidy-Hanley et al. 1997), and the transformants were selected with $100 \mu \mathrm{g} / \mathrm{mL}$ paromomycin in the presence of $1 \mu \mathrm{g} / \mathrm{mL}$ cadmium chloride. The endogenous Mac HEN1 loci were replaced by phenotypic assortment and selection using increasing concentrations of paromomycin. Complete replacement was confirmed by Southern hybridization (Supplemental Fig. S5B).

\section{DNA elimination assay}

Elimination of M, R, Cal, and Tlr1 IES elements (Austerberry et al. 1989; Katoh et al. 1993; Wells et al. 1994) was performed as described previously (see also Fig. 5A; Aronica et al. 2008) with a slight modification. In this assay, the control cells were wild-type cells possessing a neo4 marker at the $3^{\prime}$ flanking region of the HHT2-mCherry fusion gene in the macronuclei (K. Kataoka and K. Mochizuki, unpubl.). Single pairs of control and HEN1 KO strains were placed into drops of SPP medium at $\sim 8 \mathrm{~h}$ postmixing and were allowed to complete conjugation. The separated exconjugants were analyzed at $30 \mathrm{~h}$ post-mixing by nested PCR. In the first PCR, all five sets of primers - the outer primers for the four IES regions and the outer neo4 primers-were used in a single reaction. In the second PCR, only one set of inner primers was used per reaction. In this way, DNA elimination of all four IES loci in a single exconjugant could be analyzed. The control and HEN1 KO strains contain neo4 genes in their parental Macs, but their progeny lack neo4 genes in their micronuclei and new macronuclei. Samples that provided neo4 amplification products, indicating that the parental cells aborted conjugation, were excluded from the study.

\section{Progeny viability test}

Viability of progeny was analyzed as described previously (Mochizuki et al. 2002) with a slight modification: The mating pairs were isolated at $6-8 \mathrm{~h}$ post-mixing, and the growth of the cells was examined $\sim 60$ h after cloning.

\section{SUPPLEMENTAL MATERIAL}

Supplemental material can be found at http://www.rnajournal.org.

\section{ACKNOWLEDGMENTS}

We thank Yohei Kirino and Zissimos Mourelatos for the GSTmHEN1 construct and for technical advice, Johannes Popow for helping with pCp labeling, Tim Clausen for providing pGEX4T1TEV, and Martin Gorovsky for comments on the manuscript. The research leading to these results received funding from the European Research Council under the European Community's Sixth Framework Programme, from the Marie Curie Action "Early Stage Training" (grant agreement MEST-CE-2005-019676), and from the Seventh Framework Programme (FP7/2007-2013)/ERC grant agreement 204986. K.M. is a Junior Group Leader at IMBA and is funded by the Austrian Academy of Sciences.

Received November 6, 2008; accepted December 17, 2008.

\section{REFERENCES}

Akbergenov, R., Si-Ammour, A., Blevins, T., Amin, I., Kutter, C., Vanderschuren, H., Zhang, P., Gruissem, W., Meins Jr., F., Hohn, T., et al. 2006. Molecular characterization of geminivirusderived small RNAs in different plant species. Nucleic Acids Res. 34: 462-471.

Aronica, L., Bednenko, J., Noto, T., Desouza, L.V., Siu, K.W., Loidl, J., Pearlman, R.E., Gorovsky, M.A., and Mochizuki, K. 2008. Study of an RNA helicase implicates small RNA-noncoding RNA interactions in programmed DNA elimination in Tetrahymena. Genes \& Dev. 22: 2228-2241.

Austerberry, C.F., Snyder, R.O., and Yao, M.C. 1989. Sequence microheterogeneity is generated at junctions of programmed DNA deletions in Tetrahymena thermophila. Nucleic Acids Res. 17: 7263-7272.

Boutet, S., Vazquez, F., Liu, J., Beclin, C., Fagard, M., Gratias, A., Morel, J.B., Crete, P., Chen, X., and Vaucheret, H. 2003. Arabidopsis HEN1: A genetic link between endogenous miRNA controlling development and siRNA controlling transgene silencing and virus resistance. Curr. Biol. 13: 843-848.

Brennecke, J., Aravin, A.A., Stark, A., Dus, M., Kellis, M., Sachidanandam, R., and Hannon, G.J. 2007. Discrete small 
RNA-generating loci as master regulators of transposon activity in Drosophila. Cell 128: 1089-1103.

Cassidy-Hanley, D., Bowen, J., Lee, J.H., Cole, E., VerPlank, L.A., Gaertig, J., Gorovsky, M.A., and Bruns, P.J. 1997. Germline and somatic transformation of mating Tetrahymena thermophila by particle bombardment. Genetics 146: 135-147.

Chalker, D.L. and Yao, M.C. 2001. Nongenic, bidirectional transcription precedes and may promote developmental DNA deletion in Tetrahymena thermophila. Genes \& Dev. 15: 1287-1298.

Chen, X., Liu, J., Cheng, Y., and Jia, D. 2002. HEN1 functions pleiotropically in Arabidopsis development and acts in C function in the flower. Development 129: 1085-1094.

Chu, C.Y. and Rana, T.M. 2007. Small RNAs: Regulators and guardians of the genome. J. Cell. Physiol. 213: 412-419.

Cole, E.S., Cassidy-Hanley, D., Hemish, J., Tuan, J., and Bruns, P.J. 1997. A mutational analysis of conjugation in Tetrahymena thermophila. 1. Phenotypes affecting early development: Meiosis to nuclear selection. Dev. Biol. 189: 215-232.

Cox, D.N., Chao, A., Baker, J., Chang, L., Qiao, D., and Lin, H. 1998. A novel class of evolutionarily conserved genes defined by piwi are essential for stem cell self-renewal. Genes \& Dev. 12: 3715-3727.

Coyne, R.S., Nikiforov, M.A., Smothers, J.F., Allis, C.D., and Yao, M.C. 1999. Parental expression of the chromodomain protein Pddlp is required for completion of programmed DNA elimination and nuclear differentiation. Mol. Cell 4: 865-872.

Das, P.P., Bagijn, M.P., Goldstein, L.D., Woolford, J.R., Lehrbach, N.J., Sapetschnig, A., Buhecha, H.R., Gilchrist, M.J., Howe, K.L., Stark, R., et al. 2008. Piwi and piRNAs act upstream of an endogenous siRNA pathway to suppress Tc3 transposon mobility in the Caenorhabditis elegans germline. Mol. Cell. 31: 79-90.

Deng, W. and Lin, H. 2002. miwi, a murine homolog of piwi, encodes a cytoplasmic protein essential for spermatogenesis. Dev. Cell 2: 819-830.

Gorovsky, M.A., Yao, M.C., Keevert, J.B., and Pleger, G.L. 1975. Isolation of micro- and macronuclei of Tetrahymena pyriformis. Methods Cell Biol. 9: 311-327.

Grosjean, H., Droogmans, L., Roovers, M., and Keith, G. 2007. Detection of enzymatic activity of transfer RNA modification enzymes using radiolabeled tRNA substrates. Methods Enzymol. 425: 55-101.

Gunawardane, L.S., Saito, K., Nishida, K.M., Miyoshi, K., Kawamura, Y., Nagami, T., Siomi, H., and Siomi, M.C. 2007. A slicer-mediated mechanism for repeat-associated siRNA $5^{\prime}$ end formation in Drosophila. Science 315: 1587-1590.

Hamilton, A., Voinnet, O., Chappell, L., and Baulcombe, D. 2002. Two classes of short interfering RNA in RNA silencing. EMBO J. 21: 4671-4679.

Horwich, M.D., Li, C., Matranga, C., Vagin, V., Farley, G., Wang, P., and Zamore, P.D. 2007. The Drosophila RNA methyltransferase, DmHen1, modifies germline piRNAs and single-stranded siRNAs in RISC. Curr. Biol. 17: 1265-1272.

Houwing, S., Kamminga, L.M., Berezikov, E., Cronembold, D., Girard, A., van den Elst, H., Filippov, D.V., Blaser, H., Raz, E., Moens, C.B., et al. 2007. A role for Piwi and piRNAs in germ cell maintenance and transposon silencing in Zebrafish. Cell 129: 69-82.

Johnson, S.M., Lin, S.Y., and Slack, F.J. 2003. The time of appearance of the C. elegans let-7 microRNA is transcriptionally controlled utilizing a temporal regulatory element in its promoter. Dev. Biol. 259: 364-379.

Katoh, M., Hirono, M., Takemasa, T., Kimura, M., and Watanabe, Y. 1993. A micronucleus-specific sequence exists in the $5^{\prime}$-upstream region of calmodulin gene in Tetrahymena thermophila. Nucleic Acids Res. 21: 2409-2414.

Kawamura, Y., Saito, K., Kin, T., Ono, Y., Asai, K., Sunohara, T., Okada, T.N., Siomi, M.C., and Siomi, H. 2008. Drosophila endogenous small RNAs bind to Argonaute 2 in somatic cells. Nature 453: 793-797.
Keith, G. 1995. Mobilities of modified ribonucleotides on twodimensional cellulose thin-layer chromatography. Biochimie 77: $142-144$.

Kirino, Y. and Mourelatos, Z. 2007a. Mouse Piwi-interacting RNAs are $2^{\prime}-\mathrm{O}$-methylated at their $3^{\prime}$ termini. Nat. Struct. Mol. Biol. 14: 347-348.

Kirino, Y. and Mourelatos, Z. 2007b. The mouse homolog of HEN1 is a potential methylase for Piwi-interacting RNAs. RNA 13: 1397-1401.

Klahre, U., Crete, P., Leuenberger, S.A., Iglesias, V.A., and Meins Jr., F. 2002. High molecular weight RNAs and small interfering RNAs induce systemic post-transcriptional gene silencing in plants. Proc. Natl. Acad. Sci. 99: 11981-11986.

Leatherman, J.L., Levin, L., Boero, J., and Jongens, T.A. 2002. Germ cell-less acts to repress transcription during the establishment of the Drosophila germ cell lineage. Curr. Biol. 12: 1681-1685.

Lee, S.R. and Collins, K. 2006. Two classes of endogenous small RNAs in Tetrahymena thermophila. Genes \& Dev. 20: 28-33.

Lee, S.R. and Collins, K. 2007. Physical and functional coupling of RNA-dependent RNA polymerase and Dicer in the biogenesis of endogenous siRNAs. Nat. Struct. Mol. Biol. 14: 604-610.

Li, J., Yang, Z., Yu, B., Liu, J., and Chen, X. 2005. Methylation protects miRNAs and siRNAs from a $3^{\prime}$-end uridylation activity in Arabidopsis. Curr. Biol. 15: 1501-1507.

Lingel, A., Simon, B., Izaurralde, E., and Sattler, M. 2004. Nucleic acid $3^{\prime}$-end recognition by the Argonaute2 PAZ domain. Nat. Struct. Mol. Biol. 11: 576-577.

Liu, Y., Taverna, S.D., Muratore, T.L., Shabanowitz, J., Hunt, D.F., and Allis, C.D. 2007. RNAi-dependent H3K27 methylation is required for heterochromatin formation and DNA elimination in Tetrahymena. Genes \& Dev. 21: 1530-1545.

Ma, J.B., Ye, K., and Patel, D.J. 2004. Structural basis for overhangspecific small interfering RNA recognition by the PAZ domain. Nature 429: 318-322.

Malone, C.D., Anderson, A.M., Motl, J.A., Rexer, C.H., and Chalker, D.L. 2005. Germ line transcripts are processed by a Dicer-like protein that is essential for developmentally programmed genome rearrangements of Tetrahymena thermophila. Mol. Cell. Biol. 25: 9151-9164.

Meyer, E. and Chalker, D.L. 2006. Epigenetics in ciliates. In Epigenetics (eds. C.D. Allis et al.), pp. 127-150. Cold Spring Harbor Laboratory Press, Cold Spring Harbor, NY.

Mochizuki, K. 2008. High efficiency transformation of Tetrahymena using a codon-optimized neomycin resistance gene. Gene 425: 79-83.

Mochizuki, K. and Gorovsky, M.A. 2004. Conjugation-specific small RNAs in Tetrahymena have predicted properties of scan $(\mathrm{scn})$ RNAs involved in genome rearrangement. Genes \& Dev. 18: 20682073.

Mochizuki, K. and Gorovsky, M.A. 2005. A Dicer-like protein in Tetrahymena has distinct functions in genome rearrangement, chromosome segregation, and meiotic prophase. Genes \& Dev. 19: 77-89.

Mochizuki, K., Fine, N.A., Fujisawa, T., and Gorovsky, M.A. 2002. Analysis of a piwi-related gene implicates small RNAs in genome rearrangement in Tetrahymena. Cell 110: 689-699.

Newport, J. and Kirschner, M. 1982. A major developmental transition in early Xenopus embryos: II. Control of the onset of transcription. Cell 30: 687-696.

Nikiforov, M.A., Smothers, J.F., Gorovsky, M.A., and Allis, C.D. 1999. Excision of micronuclear-specific DNA requires parental expression of pdd2p and occurs independently from DNA replication in Tetrahymena thermophila. Genes \& Dev. 13: 2852-2862.

Obernosterer, G., Leuschner, P.J., Alenius, M., and Martinez, J. 2006. Post-transcriptional regulation of microRNA expression. RNA 12: 1161-1167.

Ohara, T., Sakaguchi, Y., Suzuki, T., Ueda, H., Miyauchi, K., and Suzuki, T. 2007. The $3^{\prime}$ termini of mouse Piwi-interacting RNAs are 2'-O-methylated. Nat. Struct. Mol. Biol. 14: 349-350. 
Ramachandran, V. and Chen, X. 2008. Degradation of microRNAs by a family of exoribonucleases in Arabidopsis. Science 321: 1490-1492.

Saito, K., Sakaguchi, Y., Suzuki, T., Suzuki, T., Siomi, H., and Siomi, M.C. 2007. Pimet, the Drosophila homolog of HEN1, mediates $2^{\prime}$-O-methylation of Piwi- interacting RNAs at their $3^{\prime}$ ends. Genes \& Dev. 21: 1603-1608.

Seydoux, G., Mello, C.C., Pettitt, J., Wood, W.B., Priess, J.R., and Fire, A. 1996. Repression of gene expression in the embryonic germ lineage of C. elegans. Nature 382: 713-716.

Thomson, J.M., Newman, M., Parker, J.S., Morin-Kensicki, E.M., Wright, T., and Hammond, S.M. 2006. Extensive post-transcriptional regulation of microRNAs and its implications for cancer. Genes \& Dev. 20: 2202-2207.

Vagin, V.V., Sigova, A., Li, C., Seitz, H., Gvozdev, V., and Zamore, P.D. 2006. A distinct small RNA pathway silences selfish genetic elements in the germline. Science 313: 320-324.

Viswanathan, S.R., Daley, G.Q., and Gregory, R.I. 2008. Selective blockade of microRNA processing by Lin28. Science 320: 97-100.

Wang, G. and Reinke, V. 2008. A C. elegans Piwi, PRG-1, regulates 21U-RNAs during spermatogenesis. Curr. Biol. 18: 861-867.

Wells, J.M., Ellingson, J.L., Catt, D.M., Berger, P.J., and Karrer, K.M. 1994. A small family of elements with long inverted repeats is located near sites of developmentally regulated DNA rearrangement in Tetrahymena thermophila. Mol. Cell. Biol. 14: 5939-5949.

Yang, W., Chendrimada, T.P., Wang, Q., Higuchi, M., Seeburg, P.H., Shiekhattar, R., and Nishikura, K. 2006a. Modulation of microRNA processing and expression through RNA editing by ADAR deaminases. Nat. Struct. Mol. Biol. 13: 13-21.

Yang, Z., Ebright, Y.W., Yu, B., and Chen, X. 2006b. HEN1 recognizes 21-24 nt small RNA duplexes and deposits a methyl group onto the $2^{\prime} \mathrm{OH}$ of the $3^{\prime}$ terminal nucleotide. Nucleic Acids Res. 34: $667-675$.

Yao, M.C. and Chao, J.L. 2005. RNA-guided DNA deletion in Tetrahymena: An RNAi-based mechanism for programmed genome rearrangements. Annu. Rev. Genet. 39: 537-559.

Yoo, B.C., Kragler, F., Varkonyi-Gasic, E., Haywood, V., ArcherEvans, S., Lee, Y.M., Lough, T.J., and Lucas, W.J. 2004. A systemic small RNA signaling system in plants. Plant Cell 16: 19792000.

Yu, B., Yang, Z., Li, J., Minakhina, S., Yang, M., Padgett, R.W., Steward, R., and Chen, X. 2005. Methylation as a crucial step in plant microRNA biogenesis. Science 307: 932-935.

Zalokar, M. 1976. Autoradiographic study of protein and RNA formation during early development of Drosophila eggs. Dev. Biol. 49: $425-437$. 

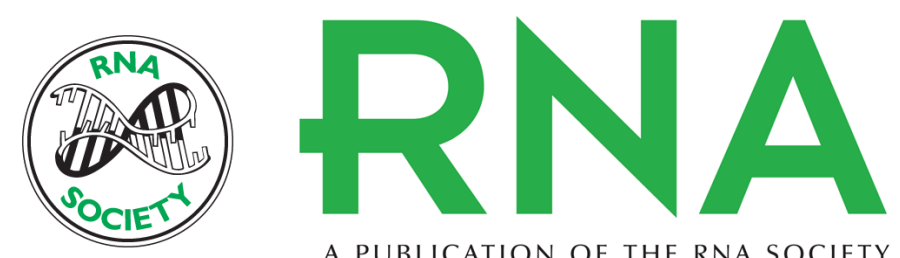

A PUBLICATION OF THE RNA SOCIETY

\section{2'-O-methylation stabilizes Piwi-associated small RNAs and ensures DNA elimination in Tetrahymena}

Henriette M. Kurth and Kazufumi Mochizuki

RNA 2009 15: 675-685 originally published online February 24, 2009

Access the most recent version at doi:10.1261/rna.1455509

\section{Supplemental http://rnajournal.cshlp.org/content/suppl/2009/02/26/rna.1455509.DC1 \\ Material}

References This article cites 57 articles, 24 of which can be accessed free at: http://rnajournal.cshlp.org/content/15/4/675.full.html\#ref-list-1

\section{License}

Email Alerting Receive free email alerts when new articles cite this article - sign up in the box at the Service top right corner of the article or click here.

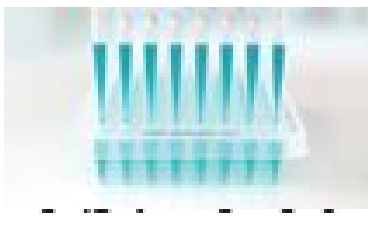

Providing Precise Solutions for your research.

To subscribe to RNA go to:

http://rnajournal.cshlp.org/subscriptions 